\title{
Prevalence and vector distributions of bovine trypanosomosis in control (Sibu Sire) and non- control (Guto Gida) districts bordering upper Anger valley of East Wollega Zone, Western Ethiopia
}

\author{
Shimelis Dagnachew ${ }^{1 *}$ and Sisay Shibeshi \\ ${ }^{1}$ University of Gondar, Faculty of Veterinary Medicine, Gondar, Ethiopia \\ *Corresponding author: dagne2121@gmail.com
}

\begin{abstract}
A cross-sectional study was conducted from December 2008 to March 2009 in two districts where tsetse control implemented (Sibu Sire district) and non-control implemented (Guto Gida district) bordering Anger river valley in East Wollega Zone, Western Ethiopia. The objectives of the study were to determine the prevalence of bovine trypanosomosis and to assess the distribution and apparent densities of vectors of the trypanosomosis. A parasitological study using buffy coat technique was employed for the determination of prevalence of trypanosomosis while monoconical traps were used for the vector studies. A total of 368 cattle randomly selected from the study population (166 in Sibu Sire and 202 in Guto Gida) districts were examined for the parasitological study. The result of parasitological study revealed that the prevalence of trypanosomosis was found to be $5.42 \%$ and $11.88 \%$ in Sibu Sire and Guto Gida districts, respectively. There was statistically significant difference in the prevalence of trypanosomosis between tsetse control implemented and non-control implemented districts $(p<0.05)$. The overall trypanosome prevalence for both districts was found to be $9 \%$ (33/368). From the infected animals the prevalence for trypanosome species was $63.6 \%$ and $36 \%$ for T. vivax and T. congolense, respectively. The mean PCV values of parasitaemic and aparasitaemic animals were $23 \%+3.7 \mathrm{SD}$ and $26 \pm 3.9 \mathrm{SD}$, respectively with a statistical significant difference $(\mathrm{P}<0.05)$. About 28 monoconical traps, 12 in Sibu Sire and 16 in Guto Gida districts were deployed for 72 hours with odour attractants for the vector studies. A total of 1478 flies were collected from both sites of which the highest fly density was Glossina tachinoides (6.8 fly/trap/day) and followed by Stomoxys (5.8 fly/trap/day) and others (0.8 fly/trap/day). There was significantly higher density of tsetse 8.4 fly/trap/day in non-control (Guto Gida) district than the control (Sibu Sire) district 0.2 fly/trap/day $(\mathrm{P}<0.05)$. Therefore implementing control of trypanosomosis with an integrated approach have paramount importance in non control areas of the study site.
\end{abstract}

Keywords: Trypanosomosis /Tsetse/ Prevalence/Density/ Sibu Sire/ Guto Gida/ Western Ethiopia. 


\section{Introduction}

Trypanosomosis is a complex disease of protozoa caused by different species of unicellular parasites found in the blood and other tissues of vertebrates including livestock, wild life and people (Uilenberg, 1998). Bovine trypanosomosis is one of the diseases that are caused by flagellated protozoan parasites belong to the genus Trypanosoma. Trypanosomosis limit the extension of natural herds particularly in Africa where the presence of tsetse fly density access to wood land and savannah areas with good grazing potential (Getachew Abebe, 2005; Getachew Abebe and Yilma Jobre, 1996). It is a serious constraint to agricultural production in extensive areas of the tsetse infested regions (Slingenebergh, 1992) which accounts over 10 million square kilometers of the tropical Africa (Budd, 1999). The disease is a major constraint in cattle, sheep, goat, equines and, in some regions, in camels and in pigs. According to Getachew Abebe (2005) the reduced capacity for work animals is also a very important factor where $80 \%$ of the traction power in African agriculture is provided by animals. Generally there is a great threat of trypanosomosis which impedes the economic development of African continent and also reasonable for the incalculable toll of human health.

Currently six species of trypanosomes are recorded in Ethiopia and the most important trypanosomes in terms of economic loss in domestic livestock are the tsetse transmitted species: Trypanosoma congolense, T. vivax and T. brucei (Getachew Abebe, 2005). Tsetse flies in Ethiopia are confined to southwestern and northwestern regions between longitude $33^{\circ}$ and $38^{\circ} \mathrm{E}$ and latitude $5^{\circ}$ and $12^{\circ} \mathrm{N}$ covers an area of $220000 \mathrm{~km}^{2}$ (NTTICC, 2004). Tsetse infested areas lie in the low lands and also in the river valleys of Abay (Blue Nile), Baro, Akobo, Didessa, Ghibe, and Omo (Langridge, 1976). Consequently, new areas are being invaded and settled communities are being continually evicted by the advancing tsetse. Five species of Glossina (G. m. submorsitans, G. pallidipes, G. tachinoides, G.f. fuscipes and G. longipennis) have been recorded in Ethiopia (Getachew Abebe, 2005). According to NTTICC (2004), tsetse transmitted animal trypanosomosis still remain as one of the largest causes of livestock production losses in Ethiopia. Therefore, the objectives of the present study were to determine the prevalence rate of bovine trypanosomosis and to assess the distribution and density of vectors in control implemented (Sibu Sire) and non-control implemented (Guto Gida) districts of East Wollega Zone, western Ethiopia. 


\section{Materials and Methods}

\section{Study Area}

The study was carried out in Sibu Sire and Guto Gida districts in East Wollega Zone of Western Ethiopia bordering Anger river valley and its tributaries . Sibu Sire district was control implemented settlement area while Guto Gida was non-control implemented settlement area. The climate alternates with long summer rain fall (June - September) and winter dry season (OctoberMay) with mean annual rain fall $1950-1100 \mathrm{~mm}$ and the altitude range from $1350-2450 \mathrm{~m}$.a.s.l. with daily temperature of $18.5^{\circ} \mathrm{c}-27.5^{\circ} \mathrm{c}$. The vegetation type of the area is characterized by riverine vegetations and savanna grass lands. Wild animals found in the vegetation areas include baboon, monkey, African buffalo, bush pig, warthog, crocodile, hyena, snakes, etc.

\section{Study Methodology}

\section{Parasitological study}

A cross-sectional type of study was conducted to determine and compare bovine trypanosomosis and vector densities in the control and non-control implemented districts of East Wollega Zone bordering the Upper Anger river valley. Random sampling technique was followed to select the animals to be examined for the study of the prevalence of bovine trypanosomosis (Thrusfield, 2007). Accordingly a total of 368 cattle 166 from control (Sibu Sire) and 202 from non-control (Guto Gida) districts were examined. The animals were categorized in to two age categories, young $(<1$ year) and adult $(>1$ year). Sample collection was done by piercing the marginal ear vein of cattle with a sterile lancet and blood from the ear vein was drawn by a heparinized capillary tube about $3 / 4^{\text {th }}$ of volume and sealed at one end with crystal seal. The capillary tubes were placed in the centrifuged at $12000 \mathrm{rpm}$ for 5 minutes (Woo, 1970). After centrifugation first the PCV was read and then the buffy coat technique was used for the detection of parasites. Thin smear were prepared for positive samples for species identification (Murray et al., 1977; Paris et al., 1982).

\section{Entomological study}

The apparent density of tsetse fly and other biting flies in relation to altitude and vegetation types were studied at selected sites of the study areas bordering Anger river valley and its tributaries. The apparent density was determined based on the mean catches of flies in traps deployed and expressed as the 
number of fly catch/trap/day (Leak et al., 1987). The flies were caught with monoconical traps baited with acetone and cow urine. A total of 28 traps, 12 in Sibu Sire district and 16 in Guto Gida district were deployed just before sunrise in the morning and in position for $72 \mathrm{hrs}$. The species of tsetse fly was identified based on morphological characteristics while other biting flies according to morphological characteristics such as size, color, wing venation and proboscis at the genus level. Sexing was done for tsetse fly just by observing the posterior end of the ventral aspect of abdomen by hand lens as a result male flies easily identified by enlarged hypophgeum (Bright et al., 1987; Walle and Shearer, 1997).

\section{Statistical Analysis}

The total prevalence rate was calculated based on the examination of positive results dividing by the total number of animals examined in the study. Descriptive and analytical statistics such as Chi square test, Kruskal Wallis test and regression analysis were used with STATA 7.0 and SPSS 15.0 version softwares. The pattern of packed cell volume (PCV) between infected and non infected animals, the prevalence rates of bovine trypanosomosis between control implemented and non-control implemented areas, age and sex of animals and densities of the fly vectors were compared.

\section{Result}

\section{Parasitological findings}

Out of the total 368 cattle examined $33(9 \%)$ cattle were positive for trypanosomosis. The prevalence were varying from $5.42 \%$ in Sibu Sire district to $11.88 \%$ in Guto Gida district with statistically significant difference $(\mathrm{P}=0.0310)$ between the control implemented and non-control implemented districts, respectively. The highest prevalence was found in the Guto Gida district of the Meti PA (16.6\%) as shown in table 1. The prevalence of trypanosomosis were not statistically significant $(\mathrm{P}>0.05)$ between different sex and age groups as indicated in tables 2 and 3 respectively. Relatively higher prevalence were found in male and young animals in both districts compared to female and adult animals. 
Table 1. Prevalence of bovine trypanosomosis in control implemented and noncontrolimplemented districts of East Wollega Zone during the study period

\begin{tabular}{lllll}
\hline District & PA & No. examined & Number positive & Prevalence (\%) \\
\hline Sibu Sire* & Beko & 52 & 2 & 3.85 \\
& Lugo & 114 & 7 & 6.14 \\
& Total & $\mathbf{1 6 6}$ & $\mathbf{9}$ & $\mathbf{5 . 4}$ \\
Guto Gida*** $^{* *}$ & Meti & 102 & 17 & 16.6 \\
& Angar Megersa & 60 & 4 & 6.6 \\
& Horo Aleltu & 40 & 3 & 7.5 \\
& Total & $\mathbf{2 0 2}$ & $\mathbf{2 4}$ & $\mathbf{1 1 . 8 ^ { * * * * }}$ \\
Overall total & & $\mathbf{3 6 8}$ & $\mathbf{3 3}$ & $\mathbf{9}$ \\
\hline
\end{tabular}

* Control implemented area , ** Non control implemented area, ${ }^{* * *}$ Significant difference between districts (P. value $=0.0310)$

Table 2. Prevalence of bovine trypanosomosis in sex categories of control implemented and non-control implemented districts of East Wollega Zone during the study period

\begin{tabular}{lllll}
\hline District & Sex & No examined & No positive & Prevalence (\%) \\
\hline Sibu Sire* & Male & 94 & 7 & 7.45 \\
& Female & 72 & 2 & 2.77 \\
Guto Gida** & Male & 112 & 14 & 12.5 \\
& Female & 90 & 10 & 11.1 \\
Total & & 368 & 33 & 9 \\
\hline
\end{tabular}

* Control implemented area

** Non control implemented area

Table 3. Prevalence of bovine trypanosomosis in age categories in both control implemented and non-control implemented districts of East Wollega Zone during the study period

\begin{tabular}{lccc}
\hline Age & No examined & No positive & Prevalence (\%) \\
\hline Young & 154 & 16 & 10.3 \\
Adult & 214 & 17 & 7.9 \\
\hline Total & 368 & 33 & 9 \\
\hline
\end{tabular}

$\operatorname{Pr}=0.418$

The proportion of trypanosome infection with species level indicated 21(64\%) were found to be infected by $T$. vivax and $12(36 \%)$ were found to be infected by $T$. congolense. The presence of high prevalence of $T$. vivax is an indicator of the importance of mechanically transmitted trypanosoma in an area where tsetse control program is undertaken. 


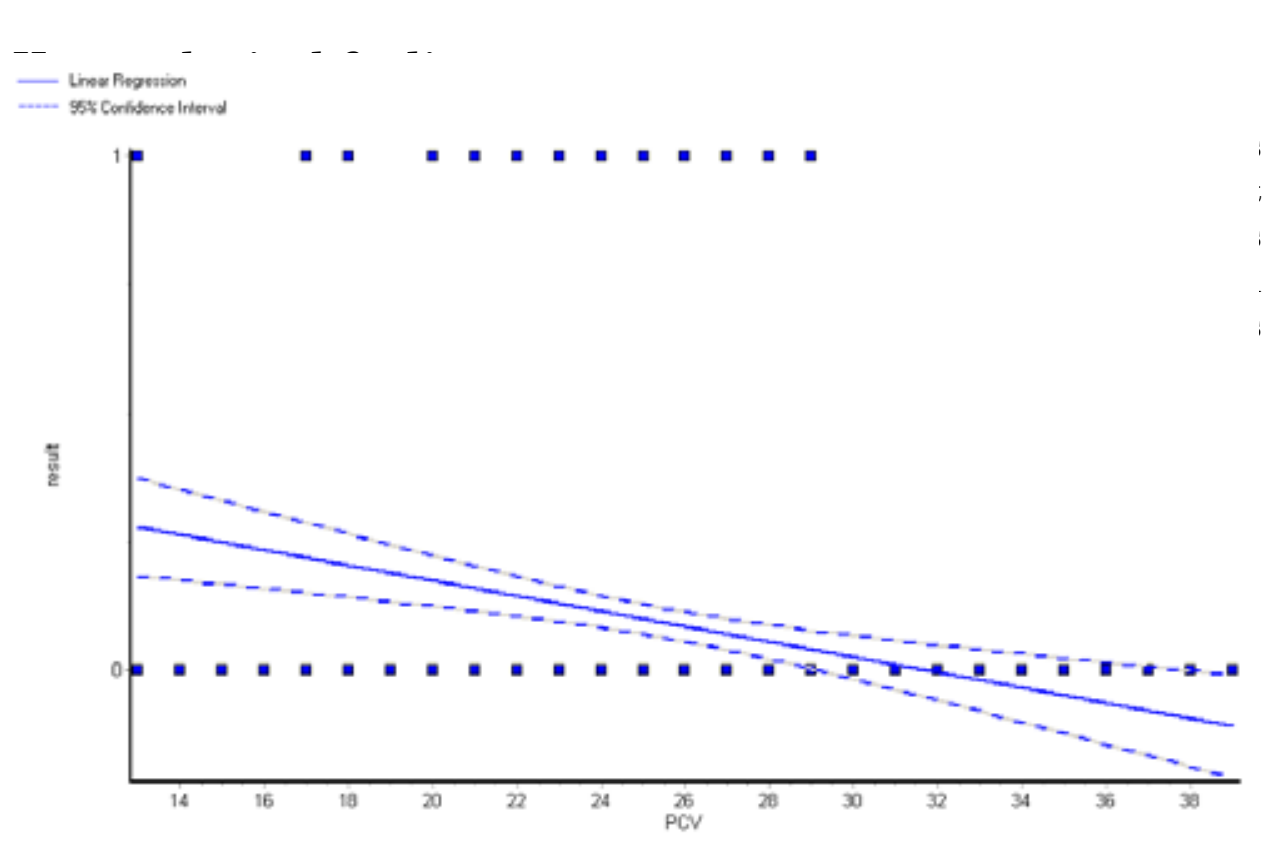

Figure 1. PCV values increase as the detection of parasitaemic animals decrease in both control and non control implemented districts of East Wollega Zone during the study period

\section{Entomological findings}

A total of 1478 flies were caught during the study period of which 302 (20.43\%) from Sibu Sire (control implemented) and 1176 (79.56\%) from Guto Gida (non control implemented) districts. The number and densities (fly/trap/day) of the different flies types caught during the study period is shown in Table 4. The highest fly density found was tsetse flies and there was statistically significant difference $(\mathrm{P}<0.05)$ between control implemented and non-control implemented areas compared to other biting flies. G. tachinoides was the only tsetse fly species found during the study period. The sex category indicated male accounts $55.4 \%$ and $44.6 \%$ were female tsetse fly. In Guto Gida district tsetse was caught from all vegetation types where the traps were deployed with an altitude range of 1269-1567 m.a.s.l. while in Sibu Sire district the highest catches were from riverine vegetation areas and the altitude distribution where tsetse fly caught was between 1337-1388 m.a.s.l. 
Table 4. The distribution and apparent densities of vectors of trypanosomosis in control and non-control districts of East Wollega Zone during the study period

\begin{tabular}{lcccccc}
\hline District & \multirow{2}{*}{$\begin{array}{c}\text { No traps } \\
\text { deployed }\end{array}$} & \multicolumn{5}{c}{ Flies identified in number and fly/trap/day(F/T/D) } \\
\cline { 3 - 7 } & 12 & Tsetse & Tabanus & Stomoxys & Hematopota & Total \\
\hline Sibu Sire* & $8(0.2)$ & $23(0.6)$ & $247(6.8)$ & $24(0.7)$ & $302(8.3)$ \\
Guto Gida** & 16 & $612(19.12)$ & $27(0.84)$ & $263(8.22)$ & $54(1.68)$ & $956(29.86)$ \\
Total & $\mathbf{2 8}$ & $\mathbf{7 2 0 ( 6 . 8 )}$ & $\mathbf{6 0 ( 0 . 6 )}$ & $\mathbf{6 1 0 ( 5 . 8 )}$ & $\mathbf{8 8 ( 0 . 8 )}$ & $\mathbf{1 4 7 8 ( 1 4 . 1 )}$ \\
\hline
\end{tabular}

* Control implemented area

** Non control implemented area

From the above table obviously indicated that tsetse fly account the highest fly caught followed by Stomoxys, Hematopota and Tabanus, respectively so that tsetse transmitted trypanosomosis is a potential threat for the local farmers and also settlement people from other parts of the region.

\section{Discussion}

Trypanosomosis is a major constraint to the utilization of large land resources and also affect livestock, cattle in particular which have a major role in agricultural economy of Ethiopia. The introduction of draught oxen in to the resettlement areas in lowland area was severely constrained by the wide spread presence of trypanosomosis (Getachew Abebe, 2005; Shimelis Dagnachew et al., 2005; Thomas Cherenet et al., 2005). The present study of prevalence of bovine trypanosomosis in Sibu Sire and Guto Gida districts of the upper Anger river valley of East Wollega Zone during the study period was found to be $5.4 \%$ and $11.8 \%$ respectively $(\mathrm{P}<0.05)$. Eventhough, the tsetse densities was high in the study area mainly in non-control implemented (Guto Gida district), the prevalence rate of bovine trypanosomosis was relatively low this might be associated to the frequent application of prophylactic treatment of animals.

The present result revealed that the trypanosome species encountered in tsetse infested area were T. vivax and T. congolense. According to the annual report of NTTICC (2002), the status of trypanosomosis before control activities was very terrible in Sibu Sire as the prevalence rate of trypanosomes in cattle was about $31 \%$. The study indicated that $T$. vivax was the predominant species in the area of Anger river valley. This may be associated to the T. vivax ability to adopt and established itself in the absence of tsetse flies transmitted by other biting flies. This has also been reported by Leak (1999) greater proportion of infection is transmitted mechanically rather than cyclically in such area (tsetse free) and T. vivax is highly transmitted in this manner than other trypanosoma 
species. The study also indicated that the difference between mean PCV values of parasitaemic and aparasitaemic cattle of the study area was significant $(\mathrm{P}<0.05)$. The mean PCV value of parasitaemic animals was $23 \% \pm 3.7 \mathrm{SD}$ and aparasitaemic animals was $26 \pm 3.9 \mathrm{SD}(\mathrm{P}<0.05)$. Measuring the mean $\mathrm{PCV}$ value is one of the indicator of a herd infected with trypanosomosis and hence the anemic status of sampled animals showed anemia (reduced PCV) values in both control and non-control districts. Getachew Abebe and Yilma Jobre (1996) reported that $60 \%$ of $T$. vivax infected cattle in the high land showed anemia below a PCV value of $20 \%$ compared to $50 \%$ of $T$. congolense and T. vivax infected cattle in the low land. It is known that the development of anemia is the most reliable indication of the progress of the trypanosome infection (ILRAD, 1988). But it can also be assumed that numerous concurrent disease and nutritional factors interfere within anemia development.

The risk of trypanosomosis is influenced by tsetse apparent density and infection rates in flies. The distribution of tsetse flies is discrete and low population in tsetse control implemented area (Sibu Sire). On the contrary higher densities of tsetse in non-control implemented area (Guto Gida) found to be a potential threat for livestock rearing and the agricultural activity in East Wollega Zone including the control sites as it can be a source of reinvasion if the control methods are not sustainable. Glossina tachinoides was the only species of tsetse fly caught in the study area. Similar findings were reported previously by various researchers that the dominant species of Glossina in the upper Anger and Didessa river valley was G. tachinoides (Leak, 1999).

\section{Conclusion}

The present study indicated that trypanosomosis is an important disease limiting livestock rearing and agricultural activity in both Sibu Sire and Guto Gida due to the presence of riverine species $G$. tachinoides. Due to tsetse control program undertaken by National Tsetse and Trypanosomosis Investigation and Control Center (NTTICC) in Sibu Sire the prevalence of trypanosomosis and the tsetse density decreased significantly compared to Guto Gida district where no control activity is conducted so far. Therefore, a progressive integrated control campaign in the Angar river valley is quite necessary to minimize the effect of trypanosomosis and to make sustainable the observed reduction both in trypanosomosis prevalence and tsetse densities which is encouraging to scale up the control program to other areas bordering Sibu Sire. 


\section{Acknowledgements}

The authors fully acknowledge the financial support of University of Gondar. The support of National Tsetse and Trypanosomosis Investigation and Control Center (NTTICC) for their logistic facilitation during field work is highly recognized.

\section{References}

Abebe, G. and Jobre, Y., 1996. Trypanosomosis. A threat to cattle production in Ethiopia. Rev. Med. Vet., 147:897-902.

Abebe, G., 2005. Review Article: Trypanosomosis in Ethiopia. Ethiop. J. Biol. Sci. 4 (1):75-121.

Brightwell, R., Dransfield, R.D., Korku, C.A., Golder, T.K., Tarimo, S.A., Mugnai, D., 1987. A New Trap for Glossina Pallidipes.Trop. Pest Manage., 33:151-159.

Budd, L. T., 1999. DFID-funded tsetse and trypanosome research and development since 1990, Volume 2, Economic Analysis. DIFID Animal Health Program.

Cherenet, T., Abebe, G., Panasam, R.J.M., Nadzr, S. and vaon den Bossche, P., 2005. A longitudinal study of bovine trypanosomosis in a tsetse free and tsetse infested zone of the Amhara Region, northwest of Ethiopia. Ethiopian veterinary Journal., 24(3): 63-74.

Dagnachew, S., Sangwan, A. K., Abebe, G., 2005. Epidemiology of bovine trypanosomosis in the Abay (Blue Nile) Basin Areas of Northwest Ethiopia. Revue D"Elevage Et De Medicine Veterinaire Des Pays Tropicaux, 58:151-157.

ILRAD, 1988. Annual Report of the International Livestock Research on Annual Disease in livestock production of tsetse affected areas of Africa. Nairobi, Kenya.

Langridge, W.P., 1976. Tsetse and Trypanosomosis Survey of Ethiopia. Ministry of Overseas Department, UK. Pp.1-40.

Leak, S. G. A., 1999. Tsetse Biology and Ecology: Their Role in the Epidemiology and Control of Trypanosomosis. CABI publishing in association with the ILRI.pp152210 .

Leak, S.K.A., Woume, K.A., Colardelle, C., Duffera, W., Feron, A., Mulingo, M., Tikubet, G., Toure, M. and Yangari, G., 1987. Determination of tsetse challenge and its 
relationship with trypanosomosis prevalence. In: Livestock production in tsetse infested areas of Africa. Nairobi, Kenya, ATLN, p. 43-52.

Murray, M., 1979. Anaemia of bovine African trypanosomosis: An overview in pathogenicity of trypanosomes (Losos, G. and Chouinard, A., eds.) Ottawa, I.D.R.C.

Murray, M., Murray, P.K. and Mc Intyre, W. I. M., 1977. An improved parasitological technique for the diagnosis of African trypanosomosis. Trans. R. Soc.Trop. Med. Hyg., 71: 325-326.

NTTICC (National Tsetse and Trypanosomosis Investigation and Control Center). Annual Report on Tsetse and Trypanosomosis Survey, 2004. Bedelle, Ethiopia.

NTTICC (National Tsetse and Trypanosomosis Investigation and Control Center). Annual report on tsetse and trypanosomosis survey, 2002. Bedelle, Ethiopia.

Paris, J., Murray, M., and Mcodimba, F., 1982. A comparative evaluation of the parasitological technique currently available for the diagnosis of African Trypanosomosis in cattle, Acta Trop., 39:307-316.

Slingenebergh, J., 1992. Tsetse control and agricultural development in Ethiopia. World Anim. Rev. 70-71: 30-36.

Thrusfield, M., 2007. Veterinary epidemiology. Blackwell, USA.

Uilenberg, G., 1998. A field guide for the diagnosis, treatment and prevention of African animal trypanosomosis. Food and Agriculture Organization of the United Nations, Rome.

Walle, R. and Shearer, D., 1997. Veterinary entomology. Arthropod ectoparasites of veterinary importance. London, UK, Champman and Hall, Pp. 141-193.

Woo, P.T.K., 1970. Haematocrit centrifugation technique for the diagnosis of African trypanosomosis. Acta trop., 27: 384-386 